\title{
N $79-24732^{7}$
}

\section{INTRODUCTION TO "SYSTEMS APPROACH"}

\author{
Gernot M. R. Winkler \\ U.S. Naval Observatory \\ Washington, D.C.
}

\section{DEFINITION AND OVERVIEW}

Systems and timekeeping have several "interfaces":

First, all systems are subject to processes, or better, processes are the essential aspect of systems. In all these processes, time is the one general, abstract parameter which relates the state of these processes to the state of all other systems. Time is, therefore, the universal system parameter (1).

Second, since time is the universal system interface, the use of clocks in systems is increasing, commensurate with our increasing demands for precision in systems interfacing. We now distinguish a class of "time ordered systems" (even though in principle all systems are time ordered) in order to emphasize the precision aspects which necessitate the use of precision clocks (2).

Third, all clocks are of necessity systems; systems in which we attempt to repeat the samc processes as identically as possible so that we obtain a uniform time scale. Therefore, any system could be used as a clock, albeit, not a very good one, e.g. we ourselves are systems, i.e. clocks, and one can read the time off our faces!

For these reasons, since clocks are systems, and are part of systems, a general overlook and introduction to the systems approach has been suggested. This appears the more appropriate since some of it, the most critical aspects of the subject, fall somewhat outside the purely engineering frame of mind; the subject is indeed trans-disciplinary. One may even be tempted to claim that these most general, but strategically essential aspects of systems belong to philosopiny in its prope sense rather than to any specific technical specialty (3).

Exhibit $\mathrm{A}$ attempts to sketch the scope of what is known today under various names such as cybernetics or General Systems Theory (GST), both mearing more or less the same (4).

What is a System?

A system is a group of interacting elements or subsystems which is organized for a purpose. This purpose is clearly external or imposed in the case of artificial or synthetic systems. In natural systems, the purpose is inherent as a heuristic principle (5). The capabilities of a system are oftc clearly reducible to those of its elements; this is the rule for technological systems of up to rathe remarkable sizes and complexities. However, very complex systems $\left(10^{8}\right.$ is a most superficial dividing mark for inter-acting elements) begin to show aspects which are qualitatively new and in principle irreducible to the qualities of the elements (6).

This is partly due to the synergistic interaction of the subsystems and partly due to principle limitations of our intellect. Any intellectual process as we know it is inherently an abstracting process with an incredible and unaccounted amount of data compression at every one of its many stages. Even our sensory perceptions are the eventual results of a most radical selection from the flood of primitive "inputs". In the complex systems environment, however, these ignored, or be ter, unknown aspects of the systems elements inevitably come to the fore and play unexpected roles. Then we are awakened to the fact that nature is (at least for us which are its "subsystems 

They are most interesting because the study of the effects of systemic measures also gives insights into the connections between GST and "information", correct information and not "noise". We must also include in the importance of information the willingness to use it. This, however, is of en prevented by preconceived notions or "policy". The example of economic systems and their intlations is notorious (14). Such a hypothetical system of $10^{8}$ subsystems, each interacting with (let us assume) $10^{4}$ others is a system of great complexity. We may take as a coarse measure the number of possible interactions per unit time, e.g. $\sim\left(\begin{array}{l}10^{8} \\ 10^{4}\end{array}\right)(15)$.

Let us now only sketch a few more points which, while they are obvious, are obviously not being acknowledged easily:

\section{THE EXISTENTIAL LEAP IN THE DARK}

Whatever we do. we are forced to act in ignorance of the total consequences of our ac - life is a leap in the dark. In systems design, however, we are not totally ignorant. We hav ule specifications and user experience with available modules as "shelf items" for building : But, the crucial point is this: If we start from overall systems specifications, we will fin. utitl many of these shelf items won't do the job. In order to stay within specifications we must custom design, build, test, debug, evaluate, change and produce many of our modules from scratch. (An item is not mature before several hundred have been operated in a system environment and the problems fed back to the debugging process). This, however, is a very expensive enterprise where one's resources may quickly disappear in guerrilla warfare with Murphy's Law (16).

The lesson is that very successful systems must not come into existence via the "grand scheme" with detailed dream-specifications. One rather has to start small (pilot project) and one should define only general system goals (17). But, one can require that all subsystems (modules) be items which have been in production and used sufficiently long to bring cut and correct all their hidden problems.

Such an approach does require a greater resourcefulness from your team, but you induce the anplication of brain power at the critical start of the project rather than for problem solving in the middle (when you hoped to be at the end). This way you don't have to leap in complete darkness.

Another point is more subtle so let us invoke an appropriately exotic example:

\section{THE SIAMESE CAT}

Let us consider the procurement of such a "system". Unfortunately, we cannot order it anymore as it used to be done: "One cat (Siamese) each . . \$50.00". Now, we need specifications and they must be complete or exhaustive - but can they be complete?

As we learn from tiology, a cat's specifications are embodied in its genes, a total of about $10^{10}$ bits of information. Prof. Carl Sagan has actually proposed (18) that we should send these $10^{10}$ bits of information by radio to an alien civilization. This would then enable the $m$ to get cats just like ours here on Earth. Now to be chariable, we assume such proposals to be in jest because they would reveal a complete ignorance of rather vital points in systems engineering and specifications! There would simply be no cat on the basis of these $10^{10}$ bits unless we could also enable that alien civilization to reproduce exactly the totality of our terrestrial environ:nent in which we mass-produce our cats. (In that case, unlikely as it is, they would aiso have to select a competent and honest contractor, a hard task, because the also impoited rales, as part of the environment, may hinder that!) 
We, therefore, conclude that we need much more than the $10^{10}$ bits - but how much?

Just the network of the cat's $10^{10}$ neurons has up to about 40 interconnections (synapses) per neuron. A description of it would require an amount of information vastly in excess of our $10^{10}$ bits in the genes. We get a glimpse of the tantast:c magnitude of this information problem but we still could not assemble the system unless we have all the information, or could we (19)? The Siamese cat has helped to shed light on the question of how nature builds such extremely complex and well functioning systems on the basis of clearly insufficient information (20).

It +urns out that one of the characteristics of the Siamese cat, the grey color of its fur, is caused by a simple gene mutation. This mutated gene cannot, as the normal gene does, produce the pigment melanine at $37^{\circ} \mathrm{C}$. Now strangely this failure also causes a second peculiarity which is not obviously related to it: The cross-eyed look and the specific behavior of this cat. The reason for this is that tiey also have some of their "wires" crossed, i.e. parts of the optical n"rves end up in the wrong cerebral hemisphere (21). This produces the need for compensation with some further changes in brain structure during growth. It also induces different behavior, that is why they look a little cross-cyed.

But, how can the failure to synthesize melanine also cause such considerable charges in the growth and structure of the nervous system? The revealing answer is that the absence of melanine in the early stages of cell division crea es a different envilunment for cell specialization which now follows different paths. What the growing organism does is that the chemistry code only modulates the environment, but the actual task of specific design is executad by the generations of dividing and specializing cells, the specific specialization leing induced by the local environment which in turn is being changed by the collective effect of the dividing (and specializing) calls.

That is what is called organic growth - the system is self designing. One can learn from nature because a living system such as the one discussed is the result of billions of selections and modifications. If we want to apply principles which correspond to organic growth, then we must also include substantial redundancy, a large reserve capacity (a large margin of performance) and sufficient feedback and internal control at the lowest possible level. Large complex systems have features which in some ways resemble an organism except that we cannot afford to use nat tre's wasteful techniques of evolution. Instead, we have to use reason and foresight. We are not yet doing too well in that department because we must remember that the public disenchantment with technology has a simple cause. It is not a consequence of too mucin thinking on our part. It is often intellectual arrogance which prevents completely thorough intellen, tual preparations. It is also often a tolerance of sloppy, superficial thinking. Therefore, a .' 1 scientific attitude. most helpful in the face of large problems, is not pride and conceit, but we admussion of ignorance and eagerness to learn.

\section{CONCLUSION}

As a summary, one may look at lexhibit C. Lr'e of truth means also hate for the half-trath and the meaningless. Humility, preached since Socrates, is often eclipsed by the mistaken desire to project an appropriate image. Patience, finally, is rarely appreciated by eager beavers who believe in frequent transplantings as a stimulus to growth. But, this is not so. To build a competent team requirs a couple of years. Any techı i al management which redirects and reorganiss every year, simply does not know what to de. It is, after all, not gimmicks which make a large system a success, but creative, thorough thinking and a very sustained effort necessary to reduce it to practice.

"Patience, renson, and time make possible the impossible." Friedrich Rïckert 


\section{EXHIBIT A}

\section{MAIN ASPECTS OF SYSTEMS THEORY \\ (GST - CYBERNETICS)}

1. Linear Systems: Feedback, optimal control, stability - systems synthesis from known element parameters. Systems architecture (22).

2. Process Statistics: Estimation theory, filtering and prediction - pattern recognition (23).

3. System Measurements and System Identification: How to characterize system performance abstractly. Links to epistemology (24). Physical causes vs. teleological causes (goals).

4. Information Th ry: I. Storage (memory), processing - semantics (meaning ' - artificial inte ligence - strategies. (Theory of games) (25).

5. Advanced Mathematical Tools: Infinite dimensional state spaces, nonlinear systems, adaptiv systems; systems modelling and simulation; catastrophe theory. Fuzzy sets, recursive an computable sets.

6. Self Organizing Systems: Emerging properties, synergy.

7. Systems, Their Environment and MAN; the Questions of Policy: Man - system interfaces, "Operations Research" (26).

8. Systen Reliability: Self repairing and redundant systems. System Life cycles and support (27). 


\section{EXHIBIT B}

\section{SOME GENERAL SYSTEMS PRINCIPLES}

1. If anything can go wrong, it will (follows from complexity which assures that eventually the ever present disturbances will test every weakness). Also, known as Murphy's Law.

2. Le Chatelier's Principle: Systems tend to oppose attempts to change them. (In order to function, however poorly, a system must be in internal dynamic equilibrium in its element interactions; therefore, a new input will immediately bring forth compensating forces) (28).

2a. Corollary: If a system should ever work well, then don't touch it!

3. Systems grow (at least due to the after thoughts) (29).

4. A complex and working system can only evolve from a simple and working system (evolutionary growth).

5. Every very complex system contains irrational features; they are necessary for functioning.

6. Symptomatic cures are useless, they only make things worse. The same is true of "systemic" cures (system-wide, sweeping measures, see principle \#2). People who don't understand systems love systemic cures!

7. An overdose of the best measures (beliefs, principles, ideas, etc.) is poisonous. (Also, known as the DIALECTICAL (30) Principle in some ideologies - namely in those who overdo this principle also!)

7a. Corollary: You can't be perfect; any attempt to be, or to make a system perfect will have disastrous consequences. (That should not mean that one must stop at the level of mediocrity!)

8. The behavior of complex systems becomes unpredictable as the complexity increases. (See also principle \#5)

8a. Corollary: Extremely complex systems are beyond human capacity to evaluate.

9. A system (composed of subsystems) which can operate well with little internal control and data flow will also be highly resistant to failures and external disturbaniss. Examples: An atomic clock with excellent crystal oscillator; A time ordered system with largely independent clocks: An organization with properly delegated authorities: A society with citizens of cornmon high moral standards.

10. The main cause of system instabilities are the delays in the action of the subsystems on cach other. Very large and complex systems, therefore, have no defined equilibrium state (static) and are, therefore, subject to corresponding process statistics (such as flicker noise, random walk, Pareto distribution, etc.) (31). (See also principle \#8)

11. Engineering of systems is a hard compromise between opposing desirable features. Systems optimization must include all aspects and is usually successful only if some flexibility of specifications is allowed (33). 


\section{EXHIBIT B (Continued)}

12. Any theoretical treatment of a system has an optimum degree of complexity (such as numbers of parameters, etc.). The optimum corresponds to a "best" separation of essential from accidental features (or of deterministic from random effects) and it is usually better to err on the simpler side (32). 


\section{EXHIBIT C}

\section{IHE CARDINAL SYSTEMS VIRTUES}

TRUTH - Keep The Coefficient Of Fiction Small.

HUMILITY - We Know Very Little, Keep Learning.

PATIENCE - Good Things Need Time. 


\section{NOTES AND REFERENCES}

(1) Time as an abstract parameter for the comparison of different processes is discussed and reviewed in

Marton, L. (ed) (1977) "Advances in Electronics and Electron Physics" Chapter 2, p. 34-45, ACADEMIC PRESS, New York ISBN 0-12-014644-4.

(2) "Time Ordered Systems" Time and Frequency, PTTI Systems - all refer in a general way to the enhanced importanc 2 of precise time or frequency in these systems. However, one has to be specific in terminology and should distinguish between (a) equal frequency, (b) accurate (a priori, without calibration) freauency, (c) internal synchronizatic.l without accounting of differential propagation delay anci/or frame ambiguity resolution, (d) internal synchronization with ambigutty resolution and/or delay accounting and (e) systems which are synchronized or coordinated (i.e. whether the time constant is short or very long) with UTC. The step from ic; to (d) is expensive, from (d) to (e) is not, yet it brings the iypical full synergisti: Jenefits of being a member of a user community. An exampie fiv (-) is the TV, while ne wert. synch:onization needs usually (d). See the following for a valid recommendation to take, in this case. the easy additional step (e).

Stover, H. A. (1973) A Time Reference Distribution Concent for a Time Division Communications Network. Proceedings 5th PTTI Conference p. 505-523.

(3) The converse seems also to be true as the following may suggest: We only have to substitute systems for the word "being" (Monas, $\mu$ ovas) and we can immediately understand in our terms the great Renaissance thinker Giordano Bruno when he postulates the universe as a hierarchy of "beings". Now Monas means something which is simple, a unity; a concept which originated from the introspective experiences of one's soul. But, this unity and separateness is deceptive and also makes his view somewhat inconsistent. The soul is due to the synthesis of the sensitivities of the body which are rooted in the (admittedly mysterious) properties of matter and these are universal and eternal (Spinoza: "Sentimus experimurque nos aeternos esse"). Therefore, there is nothing separate about the soul except the limited memory. Conversely, we may see a system as a Monas (black box) because the system concept is purely heuristic, is an intellectual device to divide the world into interesting and manageable parts with the dividing "surfaces" somewhat arbitrary (and the system "transfer function" could be called its character): in other words, the world is a hierarchy of subsystems. Now some of these subsystems have fates which can be almost independent of the rest of the universe for long times. Stable atoms and particles are such (closed) systems and we attempt to use them as clocks. However, completely closed systems can't be predicted from the outside and we can see here clearly the connections to "causality," "indeterminism" (or freedom) and similar general questions.

(4) The literature on GST as well as on the areas of Exhibit A is now enormous. A few general items follow:

Bertalanffy, Ludwig von (1968) "General Systems Theory." Braziller, N.Y. Also published by Penguin University Books, 1973.

Bertalanffy, L. and Rappaport, A. (ed) (1962) "General Systems" Ann Arbor General Systems Research.

Fox, V. (ed) (1965) "System Theory," Interscience Publication, Polytechnic Press, Brooklyn, N.Y. (Lib CCC\#65-28522). 
Klir, G. V. (ed) (1972) "Trends in GST," N.Y. (Lib CCC\#71-178143) John Wiley.

Gall, John (1975) "Systemantics," Quadrangle/The New York Times Book Company (an amusing, but a little to-be-taken-seriously farce).

Guillemin, Ernst (1963) "Theory of Linear Physical Systems," J. Wiley.

Forrester, Jay W. (1961) “Industrial Dynamics" and

Forrester, Jay W. (1971) “World Dynamics," Cambridge, Mass. (Lib CCC\#70-157752). (These last two deal with systems dynamics and model building at a large scale.)

(5) By that we mean the teleological explanations. But teleology is purely a heuristic device in science; in philosophy it may be more, much more, because such teleology can only be grounded in some metaphysics.

(6) There is no simple measure for complexity or size of the systems because such measures would have to reflect not only the number of possible interactions per unit of time, but also take into account the complexity (or the character) of the interacting subsystems. Obviously an organization of 100 people is vastly more complex than a computer with $10^{8}$ transistors but only if they interact.

(7) For a discussion of "inexhaustibility" under the quantum - mechanical point of view see the concept of "qualitative infinity of nature" in

Bohm, D. (1957) "Causality and Chance in Modern Physics," Vaan Nostrand.

In our context, however, we offer simply the conjecture: There are only subsystems, no real elements.

(8) Emergence is an important concept in British newer metaphysics:

Alexander, Samuel (1927) "Space, Time and Deity." Dover, N.Y.

Here, however, it is based on the informational aspects of epistemology and is much closer to p. $61-81$ of

Broad, C. D. (1925) "The MIND and its Place in Nature." Kegan Paul, Trench, Trubner and Company, Ltd. London.

(9) This aspect is discussed in reference (1) p. 79. But, the paper by S. Stein and F. Walls which followed this presentation gives yet another aspect of an emergent quality, i.e. better performance obtainable from a combination of two different oscillators. This is a most important subject for this conference.

(10) Here again it is hard to overemphasize to an audience so rooted in the real and material world as one is today, the fact that some insight gained by concentrated thought is the basis of everything we do today in R \& D. And, conversely, everything will become obsolete through another idea. Even more, one could support yet another conjecture: The larger the task, the more sensitive it is to the effects of creative thought.

(11) This is even true for our laws, for anything documented. Polanyi has pointed out that any system of rules can only be transmitted by tradition. example and training. This is clearly a 
precarious process and the information so transmitted is wide open to profound changes albeit from one generation of practitioners to the next. Now it is the bureaucratic ideal to leave nothing to discretion, but to embody everything in rules. But, any rule must be interpreted in a concrete case and this would require another rule. However, let us assume that all existing rules were united into a single code; then this code, obviously, could not contain prescriptions for its own interpretation, i.e., our ideal has a principal flaw. We do eventually depend upon responsible, creative interpretation. See

Polanyi, Michael (1946) "Science, Faith and Society," p. 58. University of Chicago Press. (ISBN O-226-67290-5)

Now if the above is true for a body of laws and regulations, then it is a fortiori true for technoiogy where so much depends on the skills, the tricks and trained judgment of the practitioner. In fact, a trade, even a technology, gets irretrievably lost if not practiced. That means that the great majority of know-how developed every year in our national R \& D efforts is completely wasted because of the haphazard way in which support of such groups becomes allocated. It would be wise to implement more long range funding plans of $R \& D$ teams by mission oriented agencies, such as the DoD, under this aspect.

(12) Lao-tsu ( 500 BC) “Tao-te-ching," Vintage Books 1972, ISBN O-394-71833-X.

This is an antidote to the instinctive managerial chrestomania. Ldo-tsu was the first to teach that one sees more by not focusing on a single point; that one accomplishes more by not running blindly after a single goal. Today these basic ideas of Taoism find their corroboration in the organic view and in the concept of organism.

We can consider principle \#7 of Exhibit $B$ to be of principal importance for any intellectual treatment, of large technical systems as well as of our social situation at large in which, after all, all our technical systems are embedded. Since our social structure as well as our personal attitude rests on a fundamentally inconsistent system of tacitly assumed values and principles, we try to cope by falling from one extreme application of a certain $A$ to an equally extreme one of another "good" B, after the results of the previous excess become painfully obvious. It is for this reason that successful, i.e. long term beneficial systems engineering can be done well by people who have gained that inner directed, self-disciplined attitude which helps them to abstain (out of wisdom, not interest in near term) from overdoing the "best," i.e. from maximizing the "profits." Hence, the claim about the necessary expansion of the soul; and hence, the problems created for science and engineering by the weakening of the liberal arts in education in the course of the post-Sputnik hysteria. One can safely claim that a clear awareness of the need for balance is the prerequisite for any use of intellectual tools. After all, those are more effective and potentially more disastrous than atomic bombs (which are only their by-product).

(13) That is a subject of great recent interest and has become known as "Catastrophe Theory." See e.g.

Zeeman, E. C. (1976) "Catastrophe Theory" in Scientific Aınerican, p. 65 (April).

(14) Another notorious and often tragic example is the complex of unintended effects if a specific management problem such as incompetence in some places is being attacked with general reorganizations. Such measures are of course sometimes needed such as when the organizational input-output is to change. But, as symptomatic cures they are disastrous because as systemic cures they disrupt internal communications. See particularly 
Lawrence, Paul R. (1955) "How to deal with Resistance to Change" in Harvard Business Review: "On Management," Ch. 22, Harper \& Row, ISBN O-06-011769-9 and

Drucker, Peter F. (1973) “Management,” Ch. 48, Harper \& Row, ISBN 0-06-011092-9.

Organizations are also systems, but even more important, any system effort is of necessity a team effort and the first question always to be asked is: How can we get a competent team organized and motivated? Money is only a necessary, but not sufficient resource.

(15) A large scale system has been defined as a system "whose large dimensionality makes the application of standard analysis techniques infeasible due to excessive computational requirements." A discussion on stability and optimization of such systems can be found in

Mageiron, E. F. (1976) "Topics in the Study of Inter-Connected Systems." Technical Report 664, Div. Ing. and Appl. Phys. Harvard.

On the other hand, a system has also been defined as large "when decentralized control can provide acceptable performance." See

Suri, Rajan (1978) "Resource Management in Large Systems." Technical Report \#671, Div. Appl. Sc. Harvard University, p. 185.

We propose to call a system large when it can only be dealt with by statistical measures; and very large when entirely new, irreducible features emerge. By this definition, the U.S. economy is a large, but not yet a very large system (since it can go broke through foolishness, just like a family can).

(16) Once a system is in operation, it is too late to improve poor reliability. The larger the system, the more critical will be error free operation. Now transient errors in computers, e.g. are several orders of magnitude more frequent than actual hard failures. The best way to check for transients is hardware redundancy built into critical points. In our application of time keeping, the soft failures are large clock rate changes and here the only way to filter them is clock redundancy. In general, hardware redundancy gives the capability of continuous systems diagnosis, i.e. the decoupling of reliability from other problems. See also

Percival, D. B. et al., (1975) "Time Keeping and the Reliability Problem." Proc. Ann. Frequency Control Symposium, Atlantic City, N.J. 29/412-416.

(17) The "start small" recommendation has as an alternative the advice to procesd if possible only with dividable efforts. Such efforts are those where any intermediate stages are fully beneficial. Building a system of new, high capacity trunk lines is a dividable effort. If money runs out, the effort expended was not wasted. The GPS program (certainly for time dissemination) is also largely in this class. Benefits do not have to wait until every thing is perfect. In contrast, a tunnel is clearly not a dividable effort: neither is a bridge.

(18) Sagan, Carl (1973) "Communication with Extraterrestrial Intelligence." MIT Press, Cambridge, Mass.

(19) If we accept the thesis of inexhaustibility of nature (7). then it is clear that no information will suffice to reproduce a natural system exactly. The case is entirely different for artificial systems because they represent the result of abstract functions as conceived by an intellectual process of finite steps. In this case, the ignored aspects of the material implementation play only a tolerably disturbing role - until we exceed a certain complexity. 
(20) While no finite amount of discreet (abstract bits) information may suffice to duplicate exactly our cat (which would have to include its acquired behavior), we can quantify the information which is sufficient to launch the germ cell on its development, i.e. the modification and acquisition of parts of its environment. The information is quantifiable and "simple" $\left(10^{10}\right)$ because it is relative to the material in the cell and its environment. This is where we have still hidden the inexhaustibility.

(21) Guillery, R. W. (1974) "Visual Pathways in Albinos," p. 44-54, Scientific American, May (See also lit. cited at p. 144 and Nature 252, 195-199, 1974).

(22) The practicality of digital control loops has opened up a new horizon even for simple straightforward systems such as a quartz clock which i. locked to an intermittently available reference. One is not limited anymore to the type 1 vs. type 2 (or 3?) loop question, but can now consider much more sophisticated control, i.e., along the lines discussed in reference (23d). As general background refer to chapter 17 of (27). Of particular interest to time and frequency users is also

Gardner, Floyd M. (1966) "Phaselock Techniques." John Wiley LCCC\#66-22837.

An excelli nt introduction to the advanced mathematics of extremal problems with constraints is

Gumowski, I. and Mira, C. (1968) "Optimization in Control Theory and Practice." Cambridge University Press ISBN 521-05158-4.

(23) a. Koopmans, L. H. (1974) "The Spectral Analysis of Time Series," Academic Press, N.Y. ISBN O-12-419250-5.

b. Box, G. E. P. and Jenkins, G. M. (1970) "Time Series Analysis, Forecasting and Control," Holden-Day, San Francisco. LCCC\#77-79534.

c. Morrisun, N. (1969) "Introduction to Sequential Smoothing and Prediction," McGrawHill. N.Y. LCC. \#69-17187.

d. Percival, D. (1978) "The U.S. Naval Observatory Clock Time Scales," Trans. IEEE-IM Dec.

The first two treat random variables after systematic parts hat been removed. Morrison deals with estimation of deterministic functions in the presence of additive random errors. Percival discusses the application of ARIMA models (the Box-Jenkins approach) to the ireatment of clock sets.

(24) For the treatmint of very complex systems, it is necessary to be quite clear about what we mean by "cause," "model," "law," "probabilistic explanation," etc. These are concerns of practical relevance, e.g. why do we have confidence in extrapolations with deductive nomological explanations - causal laws, when we should be very suspicious of extrapolations with a purely mathematical model? For the pure empiricist, the difference is harder to justify than for the rationalist (or for a medieval realist, or Platonist). It is no accident that the treatment of the most basic systems in science, i.e. atomic and particle physics and of the most complex, possibly inexhaustibly complex. s! .ems, i.e.. in biology, has brought about an unprecedented concern of those scientists with epistemology. As a very first starter, the following is suggested: 


\section{Reynolds, P. D. (1971) “A Primer in Theory Construction," Bobbs - Merrill, Indianapolis}

ISBN 0-672-61196-1.

(25) We can recommend a reference which is of interest beyond the scope of its title because it gives very instructive examples for difficulties of quantification and discussions of "utility," "rational behavior," etc. It is a classic:

Neumann, John von and Morgenstern, Oskar (1944) "Theory of Games and Economic Behavior," John Wiley and Sons, Inc., N.Y. ISBN O471911852.

(26) Wagner, Harvey M. (1975) "Principles of Operations Research" Second Edition, Prentice Hall. Inc. ISBN O-13-709592-9 is a textbook with many "mind expanding" exercises! To work through these 1000 pages (this author has not!) should give a firm grounding in OR.

(27) An excellent general overview is given in

Giacoletto, L. J. (ed) (1977) "Electronic Designers Handbook," Section 28 (by Trent). McGraw-Hill, ISBNO-07-023149-4. (See also note (15))

(28) A logical corollary to principle 22 of Exhibit B would be: Indirect approaches often work better (because they avoid the system reaction, at least it is delayed into ineffectiveness). The best treatment, of course, would be a thorough understanding of the causality of the system dynamics, but this will be available only in systems of modest complexity. (See also principles \#5 and \#6 of Fxhibit B.)

(29) Since these after-thoughts seem to be inevitable, it will be wise to make provisions for them, i.e. to allow for expansion in the basic architecture.

(30) Unfortunately, Hegel, the inventor of the modern sense of "dialectic," confused an epistemological with an ontological issue. In explaining things, the isolation of opposing ideas is an important intellectual device. In the ensuing discussions, the extremes find a synthesis which is a better explanation than either of its components, the thesis and antithesis. But, this purely explanatory aspect has nothing to do with a common $S$ property - the tendency to invert things. Examples are in the bible (1 Cor. 1,27); Plato (Laws 4, 705); Aristotle calls it "Reversal of roles" ("peripeteia" in Poetica VI, 18); and Toynbee in his "A Study of History" (Oxford University Press 1972, ISBN 0-517-179415) in Chs. 22 and 23 gives historical examples where failure was caused by early success.

In modern terms, Russell (Authority and line Individual, Simon and Schuster, N.Y. 1949, p. 9 and 66) suggests that Security is: isguided goal in social perfection. In the most abstract terms, one can state it as foll...s: An unbalanced, single minded application of an A will be inverted through the $S$ process into its eventual oppesite, with the effect as if $A^{-1}$ would have been applied.

Examples: A large system designed with sole emphasis on cost will, through breakdowns and deficiencies become more expensive than a reasonably generous design. A timing system designed with maximum emphasis on performance margins will, through the use of "racing horse" type clocks, become very touchy, personnel dependent and generally unreliable.

(A bureaucratic system designed for centralized efficiency with tight control and detailed procedures will become unresponsive to needs, extremely wasteful and an easy target for the most blatant corruption (sec also (11).) 
Now the tragic confusion, mentioned above, was inherited by Hegel's materialist successors who always see in such instances "contradictions" instead of real system reactions. Contradictions are a purely logical affair - we create them if we are confused and inconsistent. And, a synthesis may come in discussions, but the system will not find it - they will oscillate wildly. Contradictions are only in our theories, never in the phenomena. Those will go their way, whether we see "contradictions" or not.

(31) Mandelbrot, B. (1963) "New Methods in Statistical Economics," J. of Political Economy ?1, 421 makes the point that large systems often exhibit statistics with solite internal correlations ("Flicker noise" in clocks, "random walk" and "Pareto" distributions in economic systems). Such systems are hard to investigate because in the presence of such behavior, a basic deterministic performance cannot be discerned, i.e. perceived structures may be due to chance. We claim that this must be expected in highly complex systems with delays (which may be integration effects such as, e.g. credit expansion takes a long time until its inflationaiy effects become noticeable).

(32) This is variously known as Occam's Razor (do not use more concepts than necessary): Mach's principle of economy of thought (the simplest theory is the best); the principle of parsimony: etc. In primitive terms, it means that one should use the simplest mathematical model for smoothing because otherwise one accepts random components as part of the deterministic model which is disastrous for any extrapolation! See also the interesting numerical example of finciing the degree of a noise - contaminated unknown polynomial in

Scheid, F. (1968) "Numerical Analysis," Ch. 21. p. 250. Schaum's Outline Series, McGrawHill, N.Y.

(33) System Optimization (principle \#11) has also aspects which must be considered under the "Reversal" principle (\#7). The "Tragedy of the Commons" syndrome (see Hardin in Science $162 /$ p.1243, 1968) can be generalized in so far as optimization of the subsystems without regard to the system leads to poor performance if things work at all. This is so because "the whole is more than the sum of its parts". 